\title{
Antihypertensive treatment prescription in pediatric dialysis patients in Poland: A comparison between two nationwide studies 2003/2004-2013
}

\author{
Krzysztof Wróblewski, $, A, B, C, D, E, F$, Karolina Hincz 2, B, Monika Miklaszewska ${ }^{3, B}$, Katarzyna Zachwieja ${ }^{3, B}$, \\ Ryszard Wierciński ${ }^{4},{ }^{,}$, Roman Stankiewicz ${ }^{5, B}$, Agnieszka Firszt-Adamczyk ${ }^{5, B}$, Jacek Zachwieja ${ }^{6, B}$, Halina Borzęcka ${ }^{7}, \mathrm{~B}$, \\ Helena Ziółkowska ${ }^{8, B}$, Anna Medyńska ${ }^{9,}$, , Danuta Zwolińska ${ }^{9}$, B , Maria Szczepańska ${ }^{10, B}$, , Małgorzata Stańczyk ${ }^{11, B, C}$, \\ llona Zagożdżon ${ }^{12, B}$, Beata Leszczyńska ${ }^{8, B}$, Piotr Adamczyk ${ }^{10, B}$, Marcin Tkaczyk $k^{11,13, A, B, E, F}$ \\ ${ }^{1}$ Department of Internal Medicine and Nephrodiabetology, Medical University of Lodz, Poland \\ ${ }^{2}$ Department of Gynecology and Perinatology, Polish Mothers Memorial Hospital Research Institute, Poland \\ ${ }^{3}$ Department of Pediatric Nephrology and Hypertension, Jagiellonian University Medical College, Kraków, Poland \\ ${ }^{4}$ Department of Pediatrics and Nephrology, Medical University of Bialystok, Poland \\ ${ }^{5}$ Department of Pediatric Nephrology, Regional Hospital, Toruń, Poland \\ ${ }^{6}$ Department of Cardiology and Nephrology, Poznan University of Medical Sciences, Poland \\ ${ }^{7}$ Department of Pediatric Nephrology, Medical University of Lublin, Poland \\ ${ }^{8}$ Chair and Department of Pediatrics and Nephrology, Medical University of Warsaw, Poland \\ ${ }^{9}$ Department of Pediatric Nephrology, Wroclaw Medical University, Poland \\ ${ }^{10}$ Department of Nephrology and Dialysis, Medical University of Silesia, Zabrze, Poland \\ ${ }^{11}$ Department of Pediatrics, Immunology and Nephrology, Polish Mothers Memorial Hospital Research Institute, Poland \\ ${ }^{12}$ Department of Child and Adolescents' Nephrology and Hypertension, Medical University of Gdańsk, Poland \\ ${ }^{13}$ Division of Didactics in Pediatrics, Medical University of Lodz, Poland \\ A - research concept and design; $\mathrm{B}$ - collection and/or assembly of data; $\mathrm{C}$ - data analysis and interpretation; \\ $D$ - writing the article; $E$ - critical revision of the article; $F$ - final approval of the article
}

Address for correspondence

Krzysztof Wróblewski

E-mail: krzysztof.wroblewski@umed.lodz.pl

Funding sources

None declared

Conflict of interest

None declared

Received on 0ctober 25, 2015

Reviewed on August 15, 2016

Accepted on October 14, 2016

DOI

10.17219/acem/65823

Copyright

Copyright by Author(s)

This is an article distributed under the terms of the Creative Commons Attribution Non-Commercial License (http://creativecommons.org/licenses/by-nc-nd/4.0/)

\begin{abstract}
Background. Blood pressure in pediatric dialyzed patients is under poor control.

Objectives. The aim of the study was to assess the strategy and efficacy of antihypertensive drugs used for the treatment of hypertension in pediatric dialyzed patients in 2013 in comparison with the data collected in 2003/2004. The results have been viewed against present strategies of antihypertensive treatment in children. There is still limited data concerning the treatment of hypertension in dialyzed pediatric patients.

Material and methods. The study embraced 10 of 12 pediatric dialysis units in Poland treating 59 pediatric patients (mean age - 132 months). Collected information included present antihypertensive treatment with regard to drug classes and the dose of antihypertensive agent. The treatment was regarded as effective if both systolic and diastolic values of blood pressure were below 1.64 SDS. The results from 2013 were juxtaposed with previously analyzed data from a similar study on hypertension in dialyzed children conducted in 2003/2004.

Results. Forty subjects have been provided with antihypertensive treatment. In monotherapy and polytherapy 50\% of the subjects were treated with ACEI (enalapril and ramipril), $67.5 \%$ with amlodipine, $50 \%$ with beta-blockers. Only 10\% of the subjects were treated with angiotensin II receptor blocker (losartan). Thirty percent of the subjects received furosemide, whereas $5 \%$ were given doxazosin. Antihypertensive drugs regarded as the $2^{\text {nd }}$ and $3^{\text {rd }}$ choice in treating high blood pressure (doxazosin, beta-blockers and furosemide) were applied as monotherapy in $46 \%$ of the patients. Satisfactory control of treated blood pressure was reached in $45 \%$ of them.
\end{abstract}


Conclusions. Antihypertensive treatment in dialyzed children did not change significantly during the last decade with regard to the groups of drugs being used. Despite a wider feasibility of antihypertensive substances, the effectiveness of this therapy was still unsatisfactory.

Key words: children, treatment, arterial hypertension, dialysis

\section{Introduction}

High blood pressure is a constant element of the scenario observed in dialyzed patient with an occurrence up to $90 \% .{ }^{1}$ Many trials showed that the mortality rate following cardiovascular disease in dialyzed patients far exceeds the mortality rate observed in the healthy population. ${ }^{2}$ Recent guidelines for the management of arterial hypertension put a lot of effort into implementing a proper diagnosis and treatment of hypertension in adults, yet little has been mentioned about hypertension in children. ${ }^{3}$ The new JNC8 guidelines touch the problem of high blood pressure and chronic kidney disease in recommendation 4 and 8 , but only in patients aged 18 or over. ${ }^{4}$ Recommendations on prevention, diagnosis and treatment of hypertension in children and adolescents (published in 2009) have not been updated yet. ${ }^{5}$

In 2011, Rachel et al. reviewed antihypertensive agents used by pediatricians in treating hypertension. Their meta-analysis showed that ACE inhibitors (angiotensin-converting-enzyme inhibitors) and ARBs (angiotensin II receptor blockers) had the strongest evidence to be administered in children with kidney disease. ${ }^{6}$ So far there has been limited data regarding the prevalence and treatment of high blood pressure in dialyzed pediatric patients.

Despite the awareness of high incidence of hypertension among dialyzed pediatric patients, this population is treated ineffectively or elevated blood pressure is undertreated. ${ }^{7}$ Fluid overload, excessive sodium intake and refractory hypertension are regarded as the most common causes of hypertension on dialysis. The study of Tkaczyk et al. pointed to the fact that the incidence of hypertension in dialyzed children in Poland exceeded $55 \%$, whilst the effectiveness of antihypertensive treatment was below $60 \%{ }^{8}$ Even though there are novel drugs for antihypertensive therapy, there is still insufficient data concerning minors. Thus, the aim of the study was to assess the current incidence of hypertension among the Polish pediatric dialysis patients as well as to evaluate the effectiveness of current treatment.

\section{Material and methods}

In 2013 we obtained data from 10 pediatric dialysis centers in Poland, compared to 13 centers in 2003/2004. Two units did not respond to the survey. The study data was gathered in the same manner as in 2003. The patients were surveyed individually by a treating physician. The questionnaire included questions concerning a de- tailed medical history of primary kidney disease, renal failure, dialysis, hypertension and its treatment, as well as basic anthropometrical measures - weight, height, BMI, and the adequacy of dialysis. A patient was recognized as hypertensive when systolic and/or diastolic values were $\geq 95^{\text {th }}$ percentile (SDS $\geq 1.65$ ) concerning gender, age and height. Calculation of SDS was made with the help of Kulaga's growth charts, which were also used to adapt data from our previous 2003/2004 national survey. ${ }^{9-11}$

We analyzed the data of 59 patients under the age of 18 years: 40 boys $(67.8 \%$,) and 19 girls (32.2\%) who had been dialyzed for at least 3 months. From the group of analyzed patients we extrapolated 46 hypertensive children (77.97\%). The average age was 132 months for the hypertensive patients (who were older as compared with the average age of normotensive patients and the average age of the whole group). The average duration of dialysis was 16 months. $63.04 \%$ of patients were on peritoneal dialysis (PD), whereas $36.96 \%$ were on chronic hemodialysis (HD). Among the PD patients over 95\% were treated with automated PD. Comparing the data collected in 2003/2004 and in 2013 respectively, we noted no significant differences between age, gender, anthropometric measurements and the type of dialysis technique. A significant difference was reported in mean duration of dialysis $(\mathrm{p}=0.048)$ that proved to be shorter in 2013 and in mean incidence of hypertension $(\mathrm{p}=0.05)$ that appeared to be higher in 2013 (Table 1).

\section{Statistical analysis}

Data was evaluated by the Kołogomorow-Smirnov normality test with Lilliefor's correction. Results are expressed as median and $25^{\text {th }}-75^{\text {th }}$ interquartile range. Statistical comparisons between groups were made by 2-sided unpaired t-test or Mann-Whitney test. The $X^{2}$ and Fisher exact tests were applied to compare the categorical variables. The $\mathrm{p}$-value of less than 0.05 was considered significant. A standard score (Z-Score) was used to express a standard deviation from the mean. All analyses were completed using STATISTICA v. 12 (StatSoft Inc., USA).

\section{Results}

\section{Antihypertensive treatment}

Out of 59 patients, 40 subjects have been given antihypertensive treatment.

In the analyzed group, we found that 20/40 (50\%) subjects were treated with ACE inhibitors, 27/40 (67.5\%) sub- 
jects - with calcium channel blocker (CCB), 20/40 (50\%) subjects - with beta-blockers (BB), 12/40 (30\%) subjects with diuretics, $4 / 40(10 \%)$ subjects - with angiotensin II receptor blockers (ARB), and 2/40 (5\%) subjects - with alpha-blockers. A single-agent antihypertensive therapy was applied in $13 / 40$ (32.5\%) patients, whereas a combination therapy, defined as a concomitant use of 2 or more lowering blood pressure agents, was applied to $27 / 40$ (67.5\%) subjects. The consignment of drugs used for treating hypertension was similar to that reported in 2003/2004. In the group of $\mathrm{ACE}$ inhibitors, it was enalapril that played a pivotal role (12/20 (60\%) subjects, mean dose $0.274 \mathrm{mg} / \mathrm{kg}$ per day), followed by ramipril (8/20 (40\%) subjects, mean dose $2.188 \mathrm{mg} / \mathrm{m}^{2}$ per day). Amlodipine was the only calcium channel blocker that was used by 27 subjects with a mean dose of $0.35 \mathrm{mg} / \mathrm{kg}$ per day. In the group of betablockers, a key role was played by metoprolol and carvedilol (8/12 (66.7\%) subjects with a mean dose $1.07 \mathrm{mg} / \mathrm{kg}$ and 6/12 (50\%) subjects with mean dose $0.72 \mathrm{mg} / \mathrm{kg}$, respectively). A few patients were treated with acebutolol, atenolol and bisoprolol. Losartan was the only angiotensin II receptor blocker used by 4 patients (with mean dose of $2.12 \mathrm{mg} / \mathrm{kg}$ per day) and furosemide was the only diuretic used by 12 subjects (with the mean dose of $2.84 \mathrm{mg} / \mathrm{kg}$ per day).

In monotherapy amlodipine 5/13 (38.46\%) and betablockers $3 / 13$ (23.08\%) were the most frequently applied antihypertensive agents, whereas ACEI and doxazosin were equivalently used as the $3^{\text {rd }}$ choice $2 / 13$ (15.38\%).

In 2-drug, 3-drug and $\geq 4$-drug therapy CCB was the leading antihypertensive agent (in 73.3\%, 83.3\% and 100\%, respectively). In 2-drug therapy ACE inhibitor was used as the $2^{\text {nd }}$ add-on, but in $\geq 4$-drug therapy it was used as the $4^{\text {th }}$ add-on. The intensification of treatment by adding supplementary antihypertensive drugs increased the role of beta-blockers and diuretic in targeting blood pressure. ARB was used as an add-on drug in 3-drug therapy, and it was noted that 1 of 27 subjects was treated with ACE inhibitors and ARB simultaneously.

Table 1. Main anthropometric and clinical parameters of 2 analyzed cohorts of dialyzed children in the years 2003/2004-2013; data presented as median value and $25^{\text {th }}-75^{\text {th }}$ interquartile range

\begin{tabular}{|l|c|c|c|}
\multicolumn{1}{|c|}{\begin{tabular}{c}
\multicolumn{1}{|c|}{ Clinical } \\
parameters
\end{tabular}} & $\begin{array}{c}2013 \\
\mathrm{n}=59\end{array}$ & $\begin{array}{c}2003 / 2004 \\
\mathrm{n}=134\end{array}$ & $\begin{array}{c}\text { Statistical } \\
\text { difference }\end{array}$ \\
\hline Age (months) & $128(61-171)$ & $142(76-175)$ & $\mathrm{ns}$ \\
\hline M:F ratio & $40: 19(2.1: 1)$ & $89: 45(2: 1)$ & $\mathrm{ns}$ \\
\hline PD:HD ratio & $37: 22(1.7: 1)$ & $89: 45(2: 1)$ & $\mathrm{ns}$ \\
\hline $\begin{array}{l}\text { Duration of } \\
\text { dialysis (months) }\end{array}$ & $16(6-27)$ & $19(8-40)$ & 0.048 \\
\hline Height (cm) & $125(102-149)$ & $135(107-150)$ & $\mathrm{ns}$ \\
\hline Height SDS & $-2.2(-3.4$ to -1.0$)$ & $-2(-3.5$ to -1.3$)$ & $\mathrm{ns}$ \\
\hline Weight (kg) & $24(14.6-39.7)$ & $29(18-39)$ & $\mathrm{ns}$ \\
\hline Weight SDS & $-1.3(-1.9$ to -0.7$)$ & $-1(-2.1-0.8)$ & $\mathrm{ns}$ \\
\hline BMI (kg/m²) & $16.4(14.7-18.6)$ & $16(15-18)$ & $\mathrm{ns}$ \\
\hline BMI SDS & $-0.5(-1.1$ to -0.03$)$ & $-1(-1.1$ to -0.1$)$ & $\mathrm{ns}$ \\
\hline
\end{tabular}

\section{Drug allocation}

Initial application of ACE inhibitors in monotherapy was significantly lower $(\mathrm{p}=0.04)$ in 2013 as compared to the first-line treatment set up in 2003/2004. The overall use of ACE inhibitors was comparable $(\mathrm{p}=0.16)$ both in 2013 and in 2003/2004. In 2013 an increasing role of ACE inhibitors in treating hypertension was marked only in polytherapy.

The frequency of use of furosemide as monotherapy was significantly higher $(\mathrm{p}=0.14)$ in 2013 than in the years $2003 / 2004$.

Our analysis revealed that beta-blockers were one of the major antihypertensive agents used in mono as well as in polytherapy in 2013, whereas in 2003/2004 an increasing priority of beta-blockers was demonstrated, but not until 3-drug and 4-drug treatment. There was no significant difference in use of other groups of drugs between 2013 and 2003/2004.

\section{Efficacy of antihypertensive treatment}

Our study indicated that in $61 \%$ of patients hypertension was treated inadequately (with BP values over $95^{\text {th }}$ percentile (SDS $\geq 1.65$ ), which is similar to the results obtained in 2003/2004 (65\%). Within 10 years (Table 2), the level of underdiagnosed hypertension remained the same (10.2\% vs $11.2 \%)$.

As compared to the results of Z-score in patients given antihypertensive treatment, systolic and diastolic blood pressure values were assigned as normotensive only in 18/40 (45\%) subjects. 22/40 (55\%) patients remained hypertensive, which suggests that they were treated inadequately. What is more, Z-score results showed that in the group of patients considered as normotensive, 6/19 (31.58\%) of subjects were found to have elevated isolated systolic or diastolic blood pressure, and 3 of them had abnormally elevated values both in systolic and diastolic pressure.

In the group of hypertensive ineffectively treated subjects, isolated abnormal systolic blood pressure was diagnosed in 3/40 patients, whereas isolated abnormal diastolic pressure was noted in $13 / 40$ patients. Six out of 40 patients were hypertensive both in systolic and diastolic blood pressure.

Table 2. Comparison of blood pressure values between cohorts of dialyzed pediatric patients in the years 2003/2004-2013

\begin{tabular}{|l|c|c|c|}
\multicolumn{1}{|c|}{\begin{tabular}{c}
\multicolumn{1}{c|}{ Clinical } \\
manifestation
\end{tabular}} & $\begin{array}{c}2013 \\
\mathrm{n}=59\end{array}$ & $\begin{array}{c}2003 / 2004 \\
\mathrm{n}=134\end{array}$ & $\begin{array}{c}\text { Statistical } \\
\text { difference }\end{array}$ \\
\hline $\begin{array}{l}\text { Incidence of } \\
\text { hypertension }\end{array}$ & $46 / 59(78 \%)$ & $86 / 134(64 \%)$ & 0.05 \\
$\begin{array}{l}\text { Uncontrolled } \\
\text { hypertension } \\
\text { (percentage of } \\
\text { hypertensive patients) }\end{array}$ & $28 / 46(61 \%)$ & $56 / 86(65 \%)$ & $n$ \\
$\begin{array}{l}\text { Underdiagnosed } \\
\text { hypertension }\end{array}$ & $6 / 59(10.2 \%)$ & $\begin{array}{c}15 / 134 \\
(11.2 \%)\end{array}$ & ns \\
\hline
\end{tabular}


The effectiveness of hypertensive treatment in monotherapy was achieved in 7/13 (53.84\%) subjects, and in polytherapy in $11 / 27$ (40.74\%) subjects, whereas in $2003 / 2004$ it totaled $16 / 24(66.67 \%)$ and $14 / 46(30.43 \%)$ subjects, respectively. While comparing the results from 2013 with the results obtained in 2003/2004, no significant difference has been found in the efficacyof treatment, both in monotherapy $(\mathrm{p}=0.19)$ and in polytherapy $(\mathrm{p}=0.26)$. This finding leads to a conclusion that the rate of adequate control of blood pressure has not changed as yet.

Among 22 patients with ineffectively controlled blood pressure only $6(23.3 \%)$ were treated with $\geq 3$-drug therapy. It is to be noted that $16 / 22(73 \%)$ patients were not treated by means of all available methods of lowering blood pressure.

\section{Discussion}

The incidence of hypertension in dialyzed children is still underestimated due to the lack of sufficient data. Mistnefes et al. revealed that $76.6 \%$ of dialyzed children were hypertensive, and Kramer AM et al. found that among pediatric patients on renal replacement therapy (RRT) in Europe the prevalence of hypertension accounts for $54.4 \% .{ }^{7,12}$ These results are in accordance with our results from 2013, which marked the incidence of hypertension at the level of $77.97 \%$, and last but not least, the incidence significantly increased by ca. $14 \%(\mathrm{p}=0.05)$ as compared with the previous observation from 2003/2004.

Referring to our previous 2003/2004 report, one of the aims of this study was to elucidate thoroughly the drug allocation in mono and in polytherapy. In our work we centered on the evaluation of doctors' approach to antihypertensive treatment in dialyzed children in the last 10 years. Consequent to this, which might be regarded as a weakness, the paper itself does not deal with the causes of hypertension, the type of dialysis filters, underlying diseases and co-morbid factors. Yet, such an in-depth analysis is unique as compared to similar studies that have been published, which constitutes a remarkable strength of this work.

\section{Angiotensin-converting enzyme (ACE) inhibitors}

ACE inhibitors play a crucial role in treating hypertension. Captopril, with its in-depth study in children, is believed to be safe and effective in lowering high blood pressure; however, it has a short period of activity, which is why it has to be administered 2-3 times per day. The usage of captopril both in previous and present analysis was scarce (1 patient in respective years). In 2014 enalapril was assigned to $57.14 \%$ and ramipril to $38.09 \%$ of patients, whilst in 2003/2004 enalapril was assigned to $88.63 \%$ and ramipril to $2.27 \%$. Our data shows that newer classes of ACE inhibitors were infrequently reached for, espe- cially those that could be administered once a day. Beyond doubt, both ramipril and enalapril have been studied in hypertensive children; however, ramipril was the agent studied in pediatric patients with chronic kidney disease that demonstrated good efficacy in lowering blood pressure in this particular group. ${ }^{13-16}$ As compared to similar studies, the mean daily dose of enalapril was $0.274 \mathrm{mg} / \mathrm{kg}$, which was within the recommended range $(0.08-0.6 \mathrm{mg} / \mathrm{kg}$ per day). As there is no dose referenced to age for ramipril, this ACE inhibitor was administered at a mean dose of $2.188 \mathrm{mg}$ per day, which just moderately exceeded the minimal recommended dose (2.5-6 mg per day). ${ }^{17}$

\section{Angiotensin II receptor blocker}

The only angiotensin II receptor blocker used in antihypertensive therapy was losartan, though used infrequently in 2014 and 2003/2004 (respectively $4 / 40$ and 6/72 patients). Despite the fact that losartan was used as an add-on therapy with a mean dose $2.12 \mathrm{mg} / \mathrm{kg}$ per day far beyond exceeding the recommended initial dose $(0.75-1.44 \mathrm{mg} / \mathrm{kg}$ per day), a total efficacy of such a combined treatment was received only in $10 \%$ (1/10 subjects). The inclusion of ARB into preexisting therapy resulted in 1 case of simultaneous treatment with ACEI and ARB. ONTARGET Trial showed that the combination of ACE inhibitors and ARB prescribed for patients with renal dysfunction does not reduce poor outcomes, and may lead to more adverse drug-related events. ${ }^{18}$ Losartan has to be dosed twice a day, which may alter proper compliance with the patient. Although trials with long acting ARB were conducted in very small groups of pediatric patients, valsartan seems to have the most sufficient data for its effectiveness in lowering blood pressure in young children, yet was not in use. ${ }^{19}$

\section{Beta-blockers}

Beta-blockers are one of the most frequently chosen drugs in monotherapy in 2013 (20/40 patients vs 26/72 patients in 2003/2004). The choice of drugs remained the same for 10 years except for labetalol that was not assigned in 2013, undeniably due to its unavailability in Poland. Hence, it seems that labetalol was replaced with metoprolol.

\section{Diuretics}

The only diuretic that was used in 2013 and 2003 was furosemide, but exclusively in 2014 it was used as monotherapy in $1 / 40$ hypertensive patient.

\section{Alpha-blockers}

There is very limited data supporting the use of alpha-blockers as antihypertensive agents in children. What is more, alpha-blockers may lead to several side effects such as drowsiness. Our analysis showed that alpha- 
blockers (here uniquely doxazosin) were used as monotherapy in $15.38 \%$ of treated patients, unlike in the years $2003 / 2004$ when the assignment of alpha-blockers was observed only in a 3-drug therapy and 4-drug therapy.

\section{General comments}

Ineffective antihypertensive therapy might be attributed to dialysis-related removal of certain drugs. When choosing a proper antihypertensive therapy, it is important to take into consideration the potential removal of these agents from the circulation by hemodialysis, as well as by peritoneal dialysis. Whilst doses of antibiotics are adjusted to intermittent renal replacement therapy procedures, the dialyzability of blood pressure lowering agents is usually disrespected. It is worth pointing out that among ACE inhibitors captopril, enalapril and among beta-blockers acebutolol, atenolol and metoprolol are removed by hemodialysis. ${ }^{20}$ Our study showed that $29 \%$ hypertensive patients underwent hemodialysis and 49\% underwent peritoneal dialysis. Peritoneal dialysis, except for certain antibiotics, provides minor drug removal. The level of dialyzability in this type of RRT depends on the low volume of distribution and high protein bound. The volume of distribution of enalapril is $1.7 \mathrm{~L} / \mathrm{kg}$ and plasma protein binding is $60 \%$, thereby being eliminated by peritoneal dialysis. ${ }^{21-25}$ By contrast, the protein binding of captopril is about $30 \%$ and the volume of distribution of ramipril totals over $90 \mathrm{~L} / \mathrm{kg} .{ }^{21-25}$ In this way, neither ramipril nor losartan, carvedilol, doxazosin and furosemide are partially eliminated by standard, low-flux or peritoneal renal replacement therapy. Both enalapril and captopril are particularly recommended to be administered post-HD. Our analysis showed that among the categories of assigned antihypertensive drugs that undergo dialysis: ACE inhibitors comprised 61.9\% (enalapril and captopril) and beta-blockers - 65\% (acebutolol, atenolol and metoprolol). ${ }^{21-25}$ Thirty-one percent of patients that underwent peritoneal dialysis were treated with enalapril. Incidentally, it is worth pointing out that recent studies showed the association between dialysis-related removal of beta-blockers and a higher risk of death in elderly hemodialyzed patients. ${ }^{26}$ In our study, $11.8 \%$ of hemodialyzed hypertensive patients received in monotherapy betablocker that is eliminated by this type of RRT.

Ineffective antihypertensive therapy might also be attributed to low compliance that depends not only on the number of tablets taken per day, but also on the taste of the drugs. As most of antihypertensive agents do not exist in pediatric formulations, proper adjustment of the pediatric dose of the drug to the patient requires dividing it or smashing it to smaller particles. The taste of broken tablets is not accepted by children, except for hydrochlorothiazide, lercanidipine and candesartan, which are tasteless. ${ }^{27} \mathrm{With}$ respect to pediatric population, the influence of the taste of tablets on the level of compliance should be, in our opinion, further investigated.
Finally, in the group of ineffectively treated hypertensive subjects $32.5 \%$ presented an isolated abnormal diastolic blood pressure (DBP), which might lead to a conclusion that being focused on systolic pressure, diastolic blood pressure seems to be overlooked. There are 2 hypotheses on the presence of isolated diastolic hypertension in dialyzed population. First of all, this may be related to improper measurement when DBP seems to be overestimated by the traditional techniques of measuring. ${ }^{28}$ However, in dialyzed patients isolated abnormal DBP should not be neglected, as it may be related to a significant fluid overload and sympathetic overactivity. Recent but scarce data suggests that in dialyzed patients strict fluid management during renal replacement therapy can significantly reduce DBP within the following months of treatment. ${ }^{29,30}$ Such a fact may indicate that in a population of dialyzed patients isolated DBP can be indirect evidence for fluid overload that, in the state of preserved diuresis, could actually require an assignment of diuretics. ${ }^{31}$ Nevertheless, this group of drugs should be supported with some of the cardioprotective agents.

\section{New scopes for better blood pressure control}

Our analysis highlights 2 major problems. First and foremost, it is essential to identify all hypertensive patients. In the present study, 13\% of patients were underdiagnosed and subsequently their elevated blood pressure was not treated at all. Secondly, appropriate antihypertensive therapy should rely on evidence-based treatment as well as on pathophysiology of hypertension. As elevated blood pressure in dialyzed patients depends on reninangiotensin system overactivity (due to increased levels of angiotensin II, renin and renal ischemia), it seems that in antihypertensive therapy ACE inhibitors application should be prioritized. ACE inhibitors reduce left ventricular mass and decrease the mean arterial blood pressure. ${ }^{32,33}$ In hypertensive pediatric dialyzed population, renal artery stenosis is not frequent, and other contraindications, such as pregnancy and breast-feeding, can be neglected. Thus, this group of drugs both with ARB seems to be the safest. Our study showed that ACE inhibitors were used in monotherapy only in $15.38 \%$.

In hypertensive children not on dialysis, good blood pressure control may be achieved by long-acting ARBs; however, none of them was in use in the analyzed group of patients. ${ }^{19}$ As there is an increased level of angiotensin II that provokes sympathetic activity, beta-blockers can play an important role in better hypertension control as long as their dialyzability rate is taken into account. In hypervolemic dialyzed patients with preserved diuresis blood pressure target might be achieved by the administration of loop diuretics. ${ }^{33}$ Long-acting dihydropyridine calcium channel blockers are as safe as ACEI inhibitors, contrary to non-dihydropiridine that can amplify the effect of simultaneously administered beta-blockers. Recent studies 
on pediatric population showed that when administered in monotherapy, the effectiveness of long-acting dihydropyridine calcium channel blockers in reducing systolic as well as diastolic blood pressure is weak. On the other hand, this was the most willingly chosen group of drugs in monotherapy (38.46\%), which was pointed out in our analysis.

\section{Is there a place for other groups of drugs?}

Startling as it may seem, lately it has been noted that the application of spironolactone in dialyzed patients has considerably decreased an all-cause cardiovascular mortality rate. The study embraced adult population; however, the application of spironolactone as diuretic and cardioprotective agent in part of pediatric population with myocardial hypertrophy is still worth poring over. There was no higher incidence of hyperkaliemia in this dialyzed patients treated with spironolactone and its effect as antihypertensive agent was weak. ${ }^{34}$

\section{Conclusions}

Despite good accessibility of novel formulas in portfolio of antihypertensive drugs, the treatment of hypertension in 2013 has not changed much, as compared to the data collected in 2003/2004. Long-acting ACE inhibitors and ARB, being safe and effective, should play a pivotal role in antihypertensive treatment of dialyzed children and other agents should be used as adjunct therapy. Owing to multiple cardiovascular complications, greater effort should be put into early identification of hypertensive pediatric patients on dialysis.

\section{References}

1. Agarwal R, Nissenson AR, Batlle D, Coyne DW, Trout JR, Warnock DG. Prevalence, treatment, and control of hypertension in chronichemodialysis patients in the United States. Am J Med. 2003;115:291-297.

2. Agarwal R. Hypertension and survival in chronic hemodialysis patients - Past lessons and future opportunities. Kidney Int. 2005;67:1-13.

3. Mancia G, Fagard R, Narkiewicz K, et al. 2013 ESH/ESC quidelines for the management of arterial hypertension: The Task Force for the Management of Arterial Hypertension of the European Society of Hypertension (ESH) and of the European Society of Cardiology (ESC). Eur Heart J. 2013;34(28):2159-219.

4. James PA, Oparil S, Carter BL, et al. 2014 evidence-based guideline for the management of high blood pressure in adults: Report from the panel members appointed to the Eighth Joint National Committee (JNC 8). JAMA. 2014;311(5):507-502

5. Lurbe E, Cifkova R, Cruickshank JK, et al. Management of high blood pressure in children and adolescents: Recommendations of the European Society of Hypertension. J Hypertens. 2009;27(9):1719-1742.

6. Meyers RS, Siu A. Pharmacotherapy review of chronic pediatric hypertension. Clin Ther. 2011;33:1331-1356.

7. Kramer AM, van Stralen KJ, Jager KJ, et al. Demographics of blood pressure and hypertension in children on renal replacement therapy in Europe. Kidney Int. 2011;80(10):1092-1098.

8. Tkaczyk M, Nowicki M, Bałasz-Chmielewska I, et al. Hypertension in dialysed children: The prevalence and therapeutic approach in Poland - A nationwide survey. Nephrol Dial Transplant. 2006;21:736-742.

9. Kułaga Z, Litwin M, Tkaczyk M, et al. Polish 2010 growth references for school-aged children and adolescents. Eur J Pediatr. 2011;170:599-609.
10. Kułaga Z, Grajda A, Gurzkowska B, et al. Polish 2012 growth references for preschool children. Eur J Pediatr. 2013;172:753-761.

11. Kułaga Z, Litwin M, Grajda A, et al. Oscillometric blood pressure percentiles for Polish normal-weight school-aged children and adolescents. J Hypertens. 2012;30:1942-1954.

12. Mitsnefes M, Stablein D. Hypertension in pediatric patients on longterm dialysis: A report of the North American Pediatric Renal Transplant Cooperative Study (NAPRTCS). Am J Kidney Dis. 2005;45(2):309-315.

13. Tsuruoka S, Kitoh $Y$, Kawaguchi A, et al. Clearance of imidapril, an angiotensin-converting enzyme inhibitor, during hemodialysis in hypertensive renal failure patients: Comparison with quinapril and enalapril. J Clin Pharmacol. 2007;47(2):259-263.

14. Wells $T$, Rippley $R$, Hogg R, et al. The pharmacokinetics of enalapril in children and infants with hypertension. J Clin Pharmacol. 2001;41:1064-1074.

15. Seeman T, Dusek J, Vondrak K, Flogelova, Geier P, Janda J. Ramipril in the treatment of hypertension and proteinuria in children with chronic kidney diseases. Am J Hypertens. 2004;17:415-420.

16. Wuhl E, Mehls O, Schaefer F, ESCAPE Trial Group. Antihypertensive and antiproteinuric efficacy of ramipril in children with chronic renal failure. Kidney Int. 2004;66:768-776.

17. Spagnolo A, Giussani M, Ambruzzi AM, et al. Focus on prevention, diagnosis and treatment of hypertension in children and adolescents. Ital J Pediatr. 2013;39:20. doi: 10.1186/1824-7288-39-20.

18. Mann JF, Schmieder RE, McQueen M, et al. Renal outcomes with telmisartan, ramipril, or both, in people at high vascular risk (the ONTARGET study): A multicentre, randomised, double-blind, controlled trial. Lancet. 2008;372:547-553.

19. Flynn JT, Meyers KE, Neto JP, et al. Pediatric Valsartan Study Group. Efficacy and safety of the angiotensin receptor blocker valsar$\tan$ in children with hypertension aged 1-5 years. Hypertension. 2008;52:222-228.

20. Hörl MP, Hörl WH. Drug therapy for hypertension in hemodialysis patients. Semin Dial. 2004;17(4):288-294.

21. Olyaei AJ, Bennett WM. Principles of drug usage in dialysis patients. In: Nissenson AR, Fine RN, eds. Handbook of Dialysis Therapy. $4^{\text {th }}$ ed. Philadelphia, PA: Saunders Elsevier;2008:747-805.

22. Aronoff GR, Bennett WM, Berns JS, et al. Drug prescribing in renal failure. $5^{\text {th }}$ ed. Philadelphia, PA: American College of Physicians; 2007.

23. Ibrahim RB, Liu C, Cronin SM, et al. Drug removal by plasmapheresis: An evidence-based review. Pharmacotherapy. 2007;27:1529-1549.

24. Keller E, Reetze P, Schollmeyer P. Drug therapy in patients undergoing continuous ambulatory peritoneal dialysis: Clinical pharmacokinetic considerations. Clin Pharmacokinet. 1990;18:104-117.

25. Awdishu L, Bouchard J. How to optimize drug delivery in renal replacement therapy. Semin Dial. 2011;24(2):176-182.

26. Weir MA, Dixon SN, Fleet JL, et al. $\beta$-blocker dialyzability and mortality in older patients receiving hemodialysis. J Am Soc Nephrol. 2015;26(4):987-996.

27. Chaturvedi S, Lipszyc DH, Licht C, et al. Pharmacological interventions for hypertension in children. Evid Based Child Health. 2014;9(3):498-580.

28. Blank SG, Mann SJ, James GD, et al. Isolated elevation of diastolic blood pressure. Real or artifactual? Hypertension. 1995;26:383-389.

29. Wald R, Goldstein MB, Wald RM, et al. Correlates of left ventricular mass in chronic hemodialysis recipients. Int $J$ Cardiovasc Imaging. 2014;30(2):349-356.

30. Ferrario M, Moissl U, Garzotto F, et al. Effects of fluid overload on heart rate variability in chronic kidney disease patients on hemodialysis. BMC Nephrol. 2014;15:26.

31. Di lorio B, Di Micco L, Torraca S, et al. Variability of blood pressure in dialysis patients: A new marker of cardiovascular risk? J Nephrol. 2013;26(1):173-182.

32. Wühl E, Trivelli A, Picca S, et al. ESCAPE Trial Group. Strict bloodpressure control and progression of renal failure in children. $N$ Engl J Med. 2009;361(17):1639-1650.

33. Haskin O, Wong CJ, McCabe L, Begin B, Sutherland SM, Chaudhuri A. 44-h ambulatory blood pressure monitoring: Revealing the true burden of hypertension in pediatric hemodialysis patients. Pediatr Nephrol. 2015;30(4):653-660.

34. Matsumoto Y, Mori Y, Kageyama S, et al. Spironolactone reduces cardiovascular and cerebrovascular morbidity and mortality in hemodialysis patients. J Am Coll Cardiol. 2014;63:528-536. 